\title{
A Cryogen-Free Automated Measurement System of Stable Carbon Isotope Ratio of Atmospheric Methane
}

\author{
Taku UMEZAWA, Stephen J. ANDREWS ${ }^{1}$, and Takuya SAITO \\ National Institute for Environmental Studies, Tsukuba, Japan
}

(Manuscript received 23 June 2019, in final form 23 October 2019)

\begin{abstract}
Although methane plays an important role in climate change and atmospheric chemistry, its global budget remains quantitatively uncertain mainly because of a wide variety of source types. The stable carbon isotope ratio of atmospheric methane $\left(\delta^{13} \mathrm{C}-\mathrm{CH}_{4}\right)$ is useful for separating contributions of different source categories, but owing to the complex and laborious analysis, limited measurement data exist. We present a new system for $\delta{ }^{13} \mathrm{C}_{-} \mathrm{CH}_{4}$ measurement, optimized for the automated analysis of air samples. Although the system is designed, in principle, similarly to those in previous studies, we successfully set up the system with no use of cryogens (e.g., liquid nitrogen) and attained reproducibility sufficient to analyze atmospheric variations $(\sim 0.1 \%$ ). We performed automated continuous measurements of ambient air outside our laboratory at about hourly intervals for 2 months, which characterized imprint of local methane sources well. Future measurement operation for flask air samples from existing atmospheric monitoring programs will provide a large number of atmospheric $\delta^{13} \mathrm{C}_{-} \mathrm{CH}_{4}$ data.
\end{abstract}

Keywords methane; stable carbon isotope ratio; isotope ratio mass spectrometry

Citation Umezawa, T., S. J. Andrews, and T. Saito, 2020: A cryogen-free automated measurement system of stable carbon isotope ratio of atmospheric methane. J. Meteor. Soc. Japan, 98, 115-127, doi:10.2151/jmsj.2020-007.

\section{Introduction}

Methane $\left(\mathrm{CH}_{4}\right)$ is an important greenhouse gas emitted from both natural and anthropogenic sources, and its removal from the atmosphere occurs primarily by the reaction with tropospheric hydroxyl radical (OH) (e.g., Saunois et al. 2016; Ito et al. 2019). Worldwide observation networks have shown the long-term, interannual, seasonal, and shorter-term variations of atmospheric $\mathrm{CH}_{4}$ mole fractions. However, many of such variations observed over the past decades still

Corresponding author: Taku Umezawa, National Institute for Environmental Studies, 16-2, Onogawa, Tsukuba 3058506, Japan

E-mail: umezawa.taku@nies.go.jp

1 Present affiliation: Wolfson Atmospheric Chemistry Laboratories, Department of Chemistry, University of York, York, UK

J-stage Advance Published Date: 10 November 2019 remain quantitatively unexplained (e.g., Dlugokencky et al. 2011; Cunnold et al. 2002; Bousquet et al. 2006; Morimoto et al. 2006; Schaefer et al. 2016; Nisbet et al. 2016, 2019; Rice et al. 2016; Rigby et al. 2008, 2017; Turner et al. 2017). For effective mitigation of climate change through the reduction of $\mathrm{CH}_{4}$ emissions, accurate understanding of various $\mathrm{CH}_{4}$ emission processes and their magnitude and spatiotemporal variability is needed.

The stable carbon and hydrogen isotope ratios of $\mathrm{CH}_{4}\left(\delta^{13} \mathrm{C}-\mathrm{CH}_{4}\right.$ and $\left.\delta^{2} \mathrm{H}-\mathrm{CH}_{4}\right)$ have been used to evaluate the contributions of different $\mathrm{CH}_{4}$ source sectors by utilizing their source-specific isotope composition signatures and the kinetic isotope effects of removal processes from the atmosphere (e.g., Quay et al. 1999; Miller et al. 2002; Schwietzke et al. 2016). The isotope ratio $\delta^{13} \mathrm{C}$ (and similarly for $\delta^{2} \mathrm{H}$ ) is commonly reported using the delta notation: 


$$
\delta^{13} \mathrm{C}=\frac{R_{\text {sample }}}{R_{\text {standard }}}-1,
$$

where $R$ represents the atomic ratio ${ }^{13} \mathrm{C} /{ }^{12} \mathrm{C}$ in the sample or the standard. Measured values are conventionally reported relative to the international isotopescale VPDB (Vienna Pee Dee Belemnite). We refer to Umezawa et al. (2018) for the details of the standard scale used for atmospheric $\delta^{13} \mathrm{C}_{-} \mathrm{CH}_{4}$ measurements. Measurements of $\delta^{13} \mathrm{C}_{-} \mathrm{CH}_{4}$ in air provide useful topdown constraints to different $\mathrm{CH}_{4}$ emission categories at global (e.g., Quay et al. 1999; Miller et al. 2002; Schaefer et al. 2016; Schwietzke et al. 2016; Nisbet et al. 2016, 2019), regional (e.g., Umezawa et al. 2012; Röckmann et al. 2016; Fujita et al. 2018), and local scales (e.g., Levin et al. 1999; Lowry et al. 2001; Zazzeri et al. 2017). It has also been suggested that interannual variations of $\mathrm{OH}$ have contributed to temporal trends of atmospheric $\mathrm{CH}_{4}$ mole fraction and $\delta^{13} \mathrm{C}^{-\mathrm{CH}_{4}}$ (e.g., Schaefer et al. 2016; Rigby et al. 2017; Tyler et al. 2017). Previous studies have examined incorporation of $\delta^{13} \mathrm{C}_{-} \mathrm{CH}_{4}$ data into atmospheric chemistry transport models (e.g., Mikaloff Fletcher et al. 2004). However, given the heterogenous spatiotemporal distribution of $\mathrm{CH}_{4}$ sources and their co-locations, more data to fill the data scarce regions, not only from conventional remote marine boundary layer-based stations but also from sites with substantial imprint from regional sources, are needed to detect signals of $\mathrm{CH}_{4}$ emission changes.

Measurements of atmospheric $\delta^{13}{\mathrm{C}-\mathrm{CH}_{4}}_{4}$ have been made by offline conversion of $\mathrm{CH}_{4}$ to carbon dioxide $\left(\mathrm{CO}_{2}\right)$ and subsequent dual-inlet isotope ratio mass spectrometry (DI-IRMS) until the 1990s (e.g., Stevens and Rust 1982; Lowe et al. 1991; Quay et al. 1999). Since the 2000s, continuous-flow isotope ratio mass spectrometry (CF-IRMS) combined with gas chromatography and a combustion furnace has become common practice (Merritt et al. 1995; Miller et al. 2002; more references in Umezawa et al. 2018). These techniques have achieved measurement reproducibility of $<0.1 \%$. Guidelines reported by the community of atmospheric greenhouse gas observations suggest a compatibility goal of $0.02 \%$ for $\delta^{13} \mathrm{C}_{-} \mathrm{CH}_{4}$ measurements of well-mixed background air (World Meteorological Organization 2018). However, this is still technically difficult to achieve experimentally.

Here, we present a new CF-IRMS measurement system for $\delta^{13} \mathrm{C}^{-\mathrm{CH}_{4}}$ in air installed at the National Institute for Environmental Studies (NIES). The advantage of our system is the absence of cryogens (e.g., liquid nitrogen) in all measurement steps, which enables unattended and automated operation of the system. To our knowledge, many of the earlier studies have used cryogens (e.g., liquid nitrogen) to cool preconcentration traps (e.g., Rice et al. 2001; Miller et al. 2002; Umezawa et al. 2009; Brass and Röckmann 2010; Tokida et al. 2014), and only one laboratory reported a preconcentration trap cooled by a cryogenfree compression cooler (Brand et al. 2016). Section 2 gives descriptions of our measurement set-up. Section 3 presents performance data of our measurement system, and Section 4 our conclusions.

\section{Experimental settings}

Although detailed settings are different among laboratories (see Umezawa et al. 2018), the preprocessing procedure of CF-IRMS measurement for $\delta^{13} \mathrm{C}_{-} \mathrm{CH}_{4}$ can be commonly described as follows: (1) Sample air flows or is swept by carrier helium (He) through a preconcentration trap filled with an adsorbent maintained typically at $<-120^{\circ} \mathrm{C}$. This step collects $\mathrm{CH}_{4}$ in the sample air, and many other gases are flushed out. (2) The preconcentration trap is heated to liberate $\mathrm{CH}_{4}$ and transfer it to a cryofocusing trap. (3) The $\mathrm{CH}_{4}$ released from the cryofocusing trap passes through a separation column to achieve chromatographic separation from some remaining gases. (4) $\mathrm{The} \mathrm{CH}_{4}$ is combusted to $\mathrm{CO}_{2}$ (and water) in a high-temperature furnace. (5) The $\mathrm{CH}_{4}$-derived $\mathrm{CO}_{2}$ is further separated from co-eluted atmospheric krypton ( $\mathrm{Kr})$ using a post-combustion separation (PCS) column. The importance of this step was recognized after Schmitt et al. (2013) (see Section 3.3). (6) The $\mathrm{CH}_{4}$-derived $\mathrm{CO}_{2}$ is introduced to an IRMS. The following sections detail our measurement set-ups.

\subsection{Overview of the system}

A schematic overview of the system is shown in Fig. 1. The preconcentration and cryofocusing steps are performed using a custom-made Continuous-flow Preconcentration and Refocusing (CPR) system. CPR controls valves (V1 to V4 (FPR-ND-71-6.35-2, Fujikin Inc., Japan), four-port valve (A4C4WE, Valco Instruments, Co. Inc., USA), and six-port valves A and B (A4C6WE, Valco Instruments, Co. Inc.)) and the temperatures of the two traps (T1 and T2) via custommade software written in DaqFactory (https://www. azeotech.com/). CPR is equipped with three mass flow controllers (MFC1 (SEC-V110DM, HORIBA STEC, Co. Ltd., Japan), MFC2 (SEC-4400RO, HORIBA STEC, Co. Ltd.), and MFC3 (SEC-400MK3, HORIBA STEC, Co. Ltd.)) to regulate sample, standard, and 


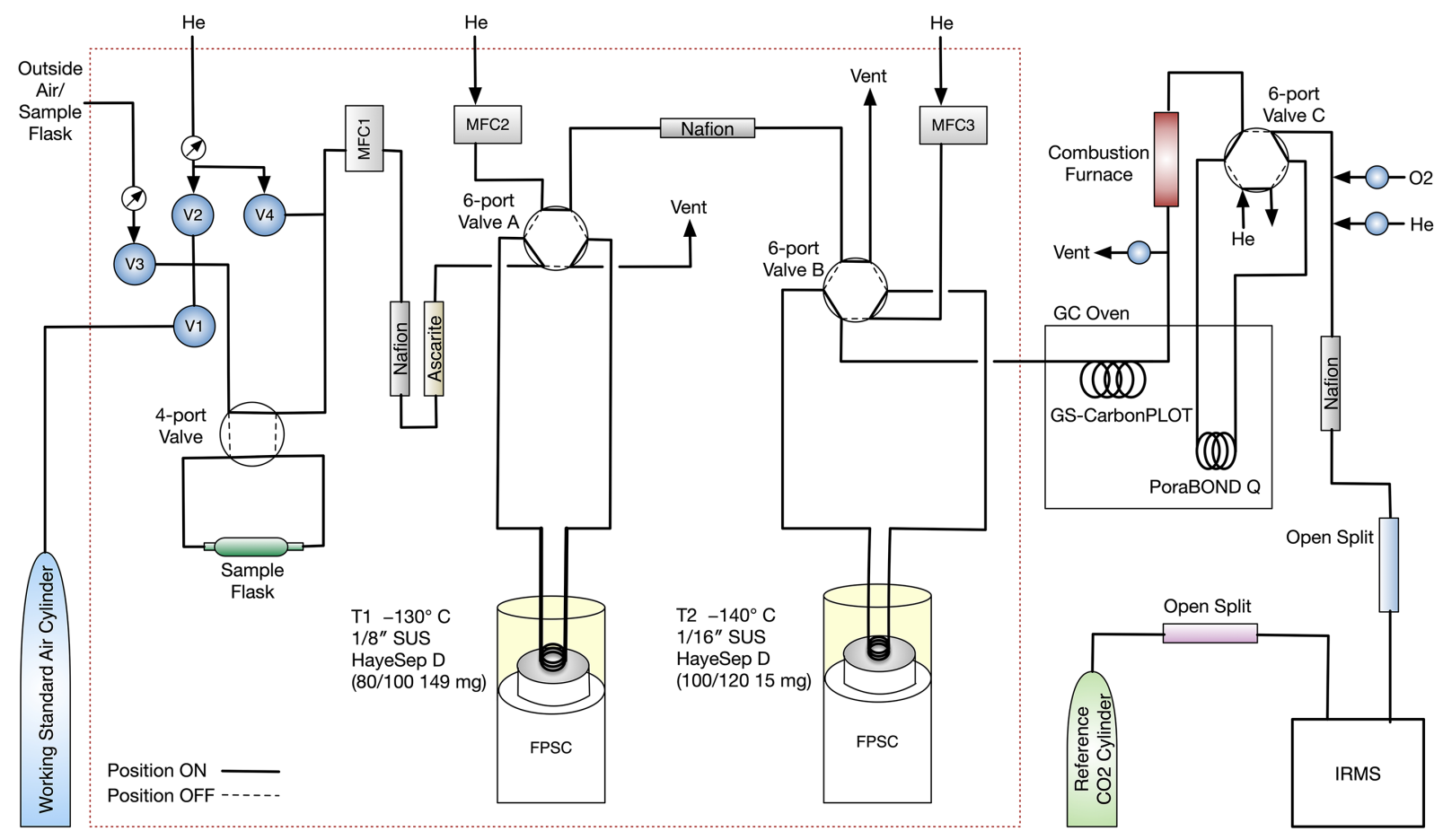

Fig. 1. A schematic overview of the CPR-GC-IRMS system. The sub-system CPR is surrounded by the dotted square. The on/off valves V1 to V4, four-port valve, and six-port valves A and B are controlled pneumatically by CPR. Solid and dashed lines of the switching valves are, respectively, referred to as ON and OFF positions in the text. MFC: mass flow controller, FPSC: free piston Stirling cooler, IRMS: isotope ratio mass spectrometer.

ultra-high-purity $\mathrm{He} \quad(>99.99995 \%$, Japan Fine Products Corp., Japan) flow through traps and the gas chromatographic (GC) section. The measurement methods of CPR (i.e., a combination of valve and trap temperature settings at different steps) can be activated by receiving a trigger signal from ISODAT (software for IRMS of ThermoFisher Scientific). CPR also sends a trigger signal to the GC (Agilent 6890, Agilent Technologies, USA), which also triggers the data acquisition method of ISODAT. Accordingly, the two software programs (DaqFactory and ISODAT) run measurement methods consistently.

\subsection{Sample, standard, and reference gases}

As shown in Fig. 1, the CPR system can introduce working standard or sample air by opening valves V1 or V3, respectively. The working standard gas is dry air containing ambient $\mathrm{CH}_{4}$ mole fraction in a 10 $\mathrm{L}$ high-pressure aluminum cylinder, which was compressed to $14.7 \mathrm{MPa}$ at NIES, Tsukuba. Pressurized (above ambient) sample flasks can be attached upstream of V3. MFC1 controls the flow rate of sample or standard air. The measured gas is introduced to sub- sequent trap T1 after passing through Nafion tubing (Sigma-Aldrich, USA) and a chemical trap filled with Ascarite II (Thomas Scientific, USA) to remove water vapor and $\mathrm{CO}_{2}$. We also have a pure $\mathrm{CO}_{2}$ reference gas (> $99.995 \%$ ) in a $47 \mathrm{~L}$ cylinder (Japan Fine Products Corp.), which is introduced into IRMS via an open split (Fig. 1). The open split is an interface between the GC section/reference gas and the IRMS. Here, the incoming gas enters an open-to-atmosphere glass tube via a capirally. This tube is purged with carrier $\mathrm{He}$, and a constant flow rate of this gas mixture is drawn by vacuum into the IRMS.

\subsection{Preconcentration trap (T1)}

The design of the preconcentration trap (T1) is schematically shown in Fig. 1. HayeSep D (80/100 mesh, $149 \mathrm{mg}$ ) adsorbent was packed into a section of $1 / 8^{\prime \prime}$ o.d. ( $2.17 \mathrm{~mm}$ i.d.) stainless steel tubing and secured with glass wool at both ends, and the tubing was then coiled at the packed section. This shape allows the tubing a relatively large contact area with an aluminum cold block cooled by a free piston Stirling cooler (FPSC; SC-UD08, Twinbird Corp., Japan). 
For temperature control, a Nichrome heating wire is wound along T1, and a temperature sensor is placed in close proximity to the packed section of the trap. The coiled trap tubing with the temperature sensor has direct surface contact to the cold block inside an insulated enclosure, which was developed based on the work by Saito and Yokouchi (2008). A cooler-based system is not disrupted by the replenishment of liquid nitrogen, and therefore, it has an advantage in automated and unattended operation.

In our current standard operation method, referencing Fig. 1, the upstream line of T1 is first flushed by sample (or standard) air at $10 \mathrm{~mL} \mathrm{~min}^{-1}$ for $3 \mathrm{~min}$ when V3 (or V1, respectively) is open and the fourport valve and six-port valve A are at ON (solid line) and OFF (dashed line) positions, respectively. Then, six-port valve A is then switched to introduce sample air to $\mathrm{T} 1$, where $\mathrm{CH}_{4}$ in sample air is adsorbed at $-130^{\circ} \mathrm{C}$ at a sample flow rate of $10 \mathrm{~mL} \mathrm{~min}{ }^{-1}$ for 10 min (i.e., $\mathrm{CH}_{4}$ in a $100-\mathrm{mL}$ sample air is collected in T1). The pressure upstream of MFC1 is kept at above ambient (controlled by a pressure regulator of the working standard air cylinder or inner pressure of a sample flask), but we cannot precisely control local pressure at T1 (downstream of MFC1). After that, the $\mathrm{T} 1$ temperature is set to $0^{\circ} \mathrm{C}$, with six-port valves $\mathrm{A}$ and $\mathrm{B}$ in the OFF position (dashed line), by which $\mathrm{CH}_{4}$ adsorbed in $\mathrm{T} 1$ is liberated and pushed by He carrier gas at $1.0 \mathrm{~mL} \mathrm{~min}^{-1}$ (MFC2) to the refocusing trap (T2). Six-port valve B is then switched to the ON position (solid line), and the temperature of $\mathrm{T} 1$ increased to $30^{\circ} \mathrm{C}$ to release and vent the remaining gases (e.g., $\mathrm{CO}_{2}, \mathrm{~N}_{2} \mathrm{O}$, and $\mathrm{H}_{2} \mathrm{O}$ ).

\subsection{Refocusing trap (T2)}

After eluting from $\mathrm{T} 1$, the $\mathrm{CH}_{4}$ from sample air is again trapped at the refocusing trap (T2). This step reduces the peak width measured on IRMS and further removes $\mathrm{N}_{2}$ and $\mathrm{O}_{2}$. T2 is $1 / 16^{\prime \prime}$ o.d. ( $0.8 \mathrm{~mm}$ i.d.) stainless steel tubing filled with $15 \mathrm{mg}$ of HayeSep D. Similarly to T1, the low temperature of T2 is achieved by contact with a cold block cooled by an FPSC (SCUF01, Twinbird Corp.). In the tubing, HayeSep D was packed into a central $\sim 5 \mathrm{~cm}$ section and secured with glass wool at both ends. The HayeSep D section of the tubing was coiled a few times, along which a Nichrome heating wire was wound and a temperature sensor was secured for temperature control. The T2 temperature is set to $-140^{\circ} \mathrm{C}$ for $4 \mathrm{~min}$ for refocusing of $\mathrm{CH}_{4}$ from $\mathrm{T} 1$, and then, the temperature is increased to $30^{\circ} \mathrm{C}$ to desorb the focused $\mathrm{CH}_{4}$ onto the GC separation column with six-port valve $\mathrm{B}$ in the
ON position (solid line) at a flow rate of $1.1 \mathrm{~mL} \mathrm{~min}^{-1}$ (MFC3).

\subsection{GC separations and combustion}

We use a GS-CarbonPLOT column $(0.32 \mathrm{~mm}$ ID, $30 \mathrm{~m}$ length, $3 \mu \mathrm{m}$ film thickness, Agilent Technologies, USA) for the GC separation. In the GC eluent, $\mathrm{CH}_{4}$ is combusted to $\mathrm{CO}_{2}$ in a combustion furnace for subsequent IRMS measurement. The conversion is achieved in alumina tubing into which braided Cuo, $\mathrm{NiO}$ and Pt wires are inserted (ThermoFisher Scientific). Our standard operation maintains the furnace at a temperature of $940^{\circ} \mathrm{C}$ as reported by Umezawa et al. (2009). The furnace is then connected to a PoraBOND Q $(0.32 \mathrm{~mm}$ ID, $50 \mathrm{~m}$ length, $5 \mu \mathrm{m}$ thickness, Agilent Technologies) column used for PCS. The two separation columns are placed in the $\mathrm{GC}$ oven set at $30^{\circ} \mathrm{C}$. The combustion furnace is regularly re-oxidized by introducing ultra-high-purity $\mathrm{O}_{2}(>99.99995 \%$, Japan Fine Products). When the furnace is re-oxidized, sixport valve $\mathrm{C}$ is switched to the OFF position (dashed line) so that $\mathrm{O}_{2}$ gas does not flow through the PCS column, and the furnace temperature is set to $600^{\circ} \mathrm{C}$ according to Sperlich et al. (2012).

\subsection{Mass spectrometric measurement}

After the PCS column, the $\mathrm{CH}_{4}$-derived peak is transferred to Nafion tubing (installed in the GCC III Interface, ThermoFisher Scientific) to remove water vapor produced in the furnace and finally to the open split (housed in ConFlo IV, ThermoFisher Scientific) for introduction to an IRMS (Delta V Advantage, ThermoFisher Scientific). The IRMS simultaneously measures signals for $\mathrm{m} / \mathrm{z}=44,45$, and 46 . Figure 2 shows a typical chromatogram obtained for the working standard air. A peak of the $\mathrm{CH}_{4}$, processed through the entire sample analytical line that was eventually converted to $\mathrm{CO}_{2}$, appears at retention time $\sim 1060 \mathrm{~s}$. Before the $\mathrm{CH}_{4}$-derived peak, peaks of air $\left(\mathrm{N}_{2}\right.$ and $\left.\mathrm{O}_{2}\right)$ and $\mathrm{Kr}$ origins appear at $\sim 880$ and $\sim 970 \mathrm{~s}$, respectively, and a peak from $\mathrm{CO}_{2}$ in sample air that was not completely removed by the analytical line appears at $\sim 1150 \mathrm{~s}$. The rectangular peaks repeated 10 times until $\sim 600 \mathrm{~s}$ are injections of $\mathrm{CO}_{2}$ reference gas from the reference open split, and the last peak is used for reference of the sample peak. Currently, we determine sample $\delta^{13} \mathrm{C}_{-} \mathrm{CH}_{4}$ values against a $\delta^{13} \mathrm{C}$ value assigned for the $\mathrm{CO}_{2}$ reference gas. The $\mathrm{CO}_{2}$ reference gas was calibrated by dual-inlet IRMS measurements on the NIES $\delta^{13} \mathrm{C}_{-} \mathrm{CO}_{2}$ scale (Mukai 2005). Our calibration strategy to reference $\delta^{13} \mathrm{C}-\mathrm{CH}_{4}$ measurements to the VPDB scale will be described in Section 3.5. 

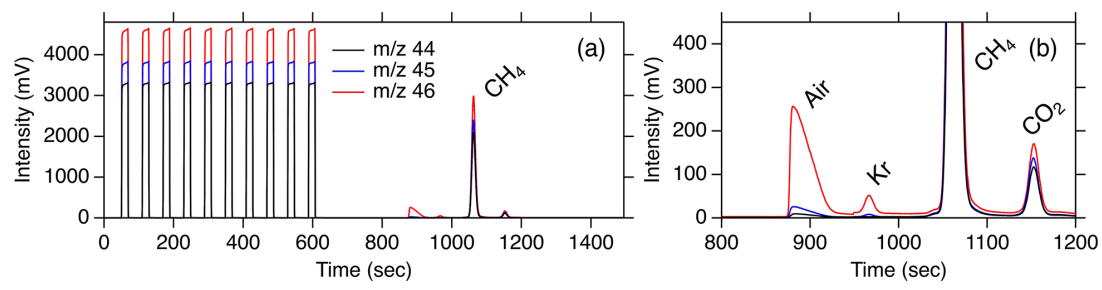

Fig. 2. (a) Typical chromatogram for a measurement of the 100-mL working standard air. Black, blue, and red solid lines represent peak intensities of $\mathrm{m} / \mathrm{z} 44,45$, and 46, respectively. Rectangular peaks repeated 10 times until $\sim 600 \mathrm{~s}$ are reference $\mathrm{CO}_{2}$ gas peaks from the reference open split. The $\mathrm{CH}_{4}$-derived $\mathrm{CO}_{2}$ peak $\left(\right.$ denoted as $\left.\mathrm{CH}_{4}\right)$ appears at $\sim 1060$ s. (b) A zoom-in of (a) for retention time around the $\mathrm{CH}_{4}$-derived $\mathrm{CO}_{2}$ peak. Denoted are gases that appear in the chromatogram and should be sufficiently separated from the $\mathrm{CH}_{4}$ peak.

\section{Results and discussion}

\subsection{Preconcentration}

Complete preconcentration of $\mathrm{CH}_{4}$ is crucial for attainting high-precision measurements of $\delta^{13} \mathrm{C}-\mathrm{CH}_{4}$. Earlier studies have shown that the adsorbent HayeSep D enables efficient preconcentration of $\mathrm{CH}_{4}$ and separation from the major air component $\left(\mathrm{N}_{2}\right.$ and $\left.\mathrm{O}_{2}\right)$ (Merrit et al. 1995; Eyer et al. 2014). We use HayeSep $\mathrm{D}$ accordingly and have tested various versions of preconcentration trap prototypes with different shapes and different amounts of HayeSep D. The amount of HayeSep D in the trap determines adsorption capacity, and the shape of the trap is important for efficient cooling and heating of the trap, since cooling of the trap in the CPR system is achieved by contact with the cold block.

To examine preconcentration efficiency in terms of HayeSep D amount and of the trap's shape, we made prototypes of $\mathrm{T} 1$ and tested them with a flame ionization detector (FID). The FID was connected after the main separation column (replaced combustion furnace and the subsequent components of Fig. 1), which precludes uncertainty that could originate from $\mathrm{CH}_{4}$ conversion to $\mathrm{CO}_{2}$ in the furnace. The prototypes included those with stainless steel tubing of $1 / 8^{\prime \prime}$ and 1/16" o.d. and with HayeSep D amount approximately ranging from 20 to $120 \mathrm{mg}$. The test with various prototypes suggested that quantitative adsorption of $\mathrm{CH}_{4}$ at $-130^{\circ} \mathrm{C}$ and below requires a HayeSep D amount of $>120 \mathrm{mg}$. In addition, contact of T1 to the cold block at a larger surface area provides a more efficient and stable adsorption of $\mathrm{CH}_{4}$. Thus, we currently use T1 packed with $149 \mathrm{mg}$ of HayeSep D in a coil of $1 / 8^{\prime \prime}$ o.d. stainless steel tubing. We also tested a prototype with $280 \mathrm{mg}$ of HayeSep D, but such further increase of HayeSep D amount did not increase the $\mathrm{CH}_{4}$ peak amplitude, and it could increase the amount of interfering air components adsorbed on the trap. A possible explanation is that the increased pressure inside the trap because of the enhanced flow resistance may trap a larger amount of $\mathrm{N}_{2}$ and $\mathrm{O}_{2}$. We therefore conclude that the amount of HayeSep D packed into the trap should not be increased further once adequate peak amplitude is achieved.

Figure 3 shows the response of the current T1 trap to the T1 setpoint temperature. We find stable $\delta^{13} \mathrm{C}-\mathrm{CH}_{4}$ and peak area $(\mathrm{m} / \mathrm{z}=44)$ values at $-125^{\circ} \mathrm{C}$ and below. This trap was also examined for response to sample air volume passing through $\mathrm{T} 1$ at $-130^{\circ} \mathrm{C}$ (Fig. 4). The peak area increases linearly with the volume of sample air that passes through T1 when the trapping time is no longer than $18 \mathrm{~min}$ (i.e., sample volume of 180 $\mathrm{mL}$ or smaller). However, a longer sample flow does not increase the peak area, and for trapping times of 20-50 min, the peak areas are almost the same, indicating a partial breakthrough of $\mathrm{CH}_{4} \cdot \delta^{13} \mathrm{C}-\mathrm{CH}_{4}$ values are stable for trapping times of 7-18 $\mathrm{min}$, whereas deviations occur outside of that range. The large variability for trapping times of $>20 \mathrm{~min}$ is due to the partial breakthrough of $\mathrm{CH}_{4}$ corresponding to the peak area response. On the other hand, for trapping times of $5 \mathrm{~min}$ and shorter, $\delta^{13} \mathrm{C}-\mathrm{CH}_{4}$ clearly increases with decreasing T1 trapping time. This increase in $\delta^{13} \mathrm{C}-\mathrm{CH}_{4}$ is due to the non-linearity of the IRMS. We confirmed the same magnitude of $\delta^{13} \mathrm{C}-\mathrm{CH}_{4}$ increase when the amount of reference $\mathrm{CO}_{2}$ gas injected is reduced. A similar non-linearity trend in $\delta^{13} \mathrm{C}-\mathrm{CH}_{4}$ for small peak amplitudes was reported by Umezawa et al. (2009).

In our set-up, we found that the $\mathrm{CH}_{4}$ adsorbed on $\mathrm{T} 1$ can be released adequately at a temperature of $-80^{\circ} \mathrm{C}$ and above. This temperature of $\mathrm{CH}_{4}$ release is consistent with $-85^{\circ} \mathrm{C}$ reported by Brass and Röckmann (2010). Some earlier studies adopted a stepwise 


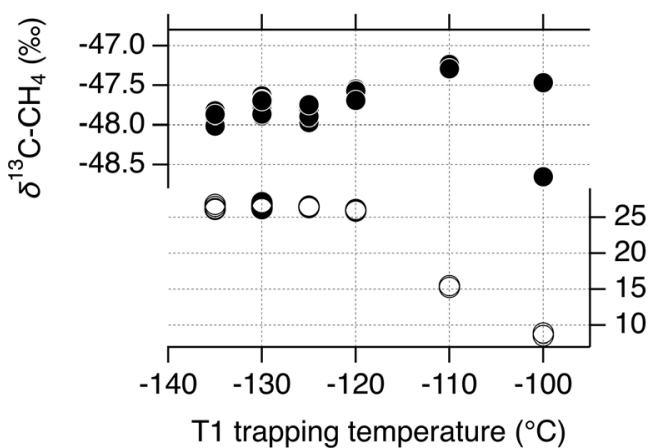

Fig. 3. $\quad \delta^{13} \mathrm{C}_{-} \mathrm{CH}_{4}$ (closed circles, left axis) and peak area $(\mathrm{m} / \mathrm{z}=44$, open circles, right axis) relationships as a function of T1 temperature.

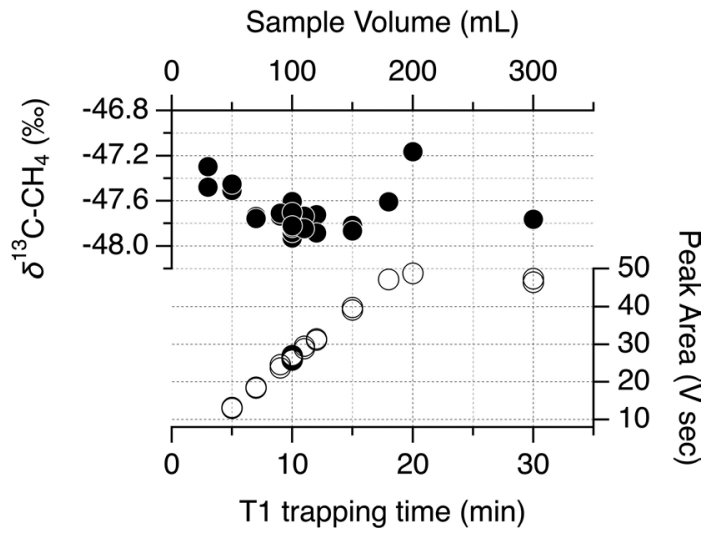

Fig. 4. $\quad \delta^{13} \mathrm{C}-\mathrm{CH}_{4}$ (closed circles, left axis) and peak area (open circles, right axis) relationships as a function of time during the preconcentration step at T1. Corresponding sample air volume is shown on the top axis.

temperature increase of the preconcentration trap (first approximately $-80^{\circ} \mathrm{C}$ and finally above $0^{\circ} \mathrm{C}$ ) because it practically separates $\mathrm{CH}_{4}$ from other gases adsorbed simultaneously $\left(\mathrm{N}_{2}, \mathrm{O}_{2}, \mathrm{CO}_{2}, \mathrm{~N}_{2} \mathrm{O}\right.$, and $\mathrm{H}_{2} \mathrm{O}$ ) (Umezawa et al. 2009; Brass and Röckmann 2010; Eyer et al. 2016). In this respect, we experimentally found that the peak of air $\left(\mathrm{N}_{2}\right.$ and $\left.\mathrm{O}_{2}\right)$ detected on IRMS is reduced by setting the T1-to-T2 transfer temperature lower (closer to $-80^{\circ} \mathrm{C}$ ). On the other hand, it was also found that a rapid increase of $\mathrm{T} 1$ temperature to $0^{\circ} \mathrm{C}$ allows a more efficient and stable transfer of $\mathrm{CH}_{4}$ from $\mathrm{T} 1$ to $\mathrm{T} 2$ at the same transfer flow. We avoid stepwise temperature control during the transfer, but instead, we reduce the air-originated contamination peak by switching off the open split capillary (Section

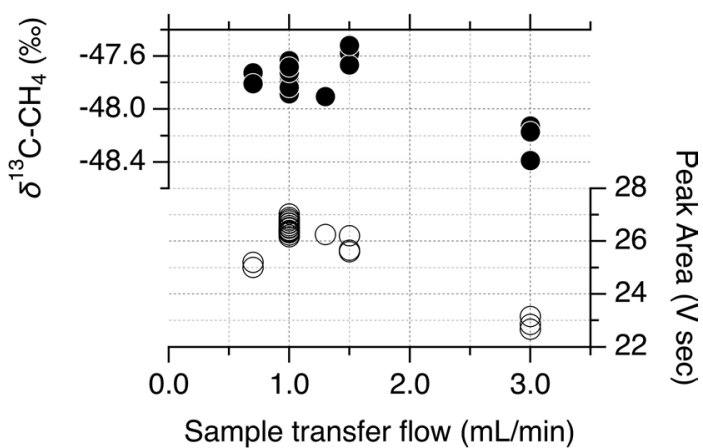

Fig. 5. $\quad \delta^{13} \mathrm{C}-\mathrm{CH}_{4}$ (closed circles, left axis) and peak area (open circles, right axis) relationships against carrier He-flow rate when $\mathrm{CH}_{4}$ in sample air is transferred from $\mathrm{T} 1$ to $\mathrm{T} 2$.

3.4). Figure 5 shows how $\delta^{13}{\mathrm{C}-\mathrm{CH}_{4}}_{4}$ and peak area change with He flow rate during the T1-to-T2 transfer. The largest peak was obtained with a flow rate of 1.0 $\mathrm{mL} \mathrm{min}^{-1}$. The lower flow rate cannot transfer the $\mathrm{CH}_{4}$ adsorbed on $\mathrm{T} 1$ completely within $4 \mathrm{~min}$, and the higher flow rates indicate incomplete refocusing at $\mathrm{T} 2$, where the heavier isotopologue ${ }^{13} \mathrm{CH}_{4}$ partly breaks away. The transfer time was also optimized (not shown), with both shorter and longer times resulting in a reduced peak because of incomplete transfer and partial liberation from $\mathrm{T} 2$, respectively.

\subsection{Refocusing}

For refocusing of $\mathrm{CH}_{4}$, previous studies have used capillary tubing cooled by liquid nitrogen (e.g., Rice et al. 2001; Umezawa et al. 2009; Tokida et al. 2014), but a recent study with a compression cooler (Brand et al. 2016) uses $1 / 16^{\prime \prime}$ o.d. stainless steel tubing as per this study. For our first attempt, we used 1/32" o.d. tubing because smaller-diameter tubing would lead to a sharper peak. However, we found inadequate $\mathrm{CH}_{4}$ adsorption with 1/32" tubing. Our experiments showed that peak areas $(\mathrm{m} / \mathrm{z}=44)$ obtained from 1/32"-tubing T2 (HayeSep D $8 \mathrm{mg}$ ) are only half as large as those from 1/16"-tubing T2 (HayeSep D 15 $\mathrm{mg}$ ). Even an increased amount of HayeSep D (17 $\mathrm{mg}$ ) in $1 / 32^{\prime \prime}$ tubing did not yield stable peak areas at temperatures of $-130^{\circ} \mathrm{C}$ and below, whereas $1 / 16^{\prime \prime}$ tubing T2 achieved quantitative adsorption at this temperature. The 1/32"- and 1/16"-tubing T2 traps with similar amounts of HayeSep D $(\sim 15 \mathrm{mg})$ are different in their shape. Since the former requires a larger length for the same amount of adsorbent, it needs to be more repeatedly coiled to fit into the cold 


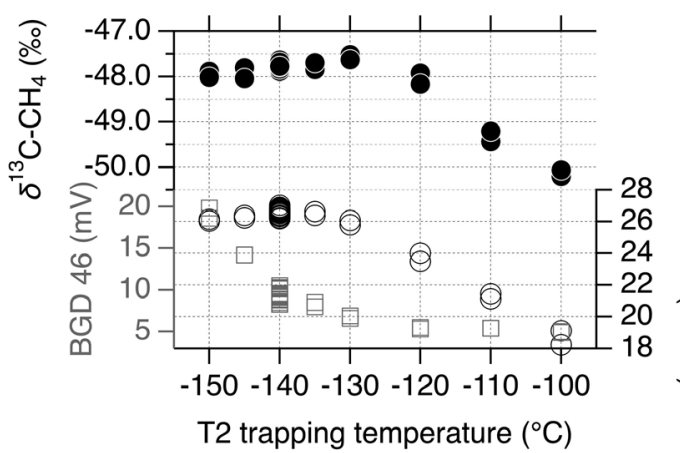

Fig. 6. $\quad \delta^{13} \mathrm{C}-\mathrm{CH}_{4}$ (closed circles, top left axis), peak area (open circles, right axis), and background (BGD) value of $\mathrm{CH}_{4}$-derived peak for $\mathrm{m} / \mathrm{z} 46$ (gray open squares, bottom left axis) as a function of T2 temperature.

block contact configuration. It is likely that the larger diameter of the latter helps in cooling more efficiently the adsorbent packing. It is also important to note that the difference in tubing diameter changes the local pressure and linear velocity inside the trap, which can considerably affect trapping of $\mathrm{CH}_{4}$ and contributed to the above result.

Figure 6 shows how the $\mathrm{CH}_{4}$ peak changed with T2 temperature settings. The $\mathrm{CH}_{4}$ peak increases with decreasing $\mathrm{T} 2$ temperature, and its magnitude reaches a stable value at $-130^{\circ} \mathrm{C}$ and below. The $\delta^{13} \mathrm{C}^{-} \mathrm{CH}_{4}$ trend indicates incomplete trapping of heavier ${ }^{13} \mathrm{CH}_{4}$ at temperatures higher than $-130^{\circ} \mathrm{C}$. Also plotted are the background values of the $\mathrm{CH}_{4}$ peak ( $\mathrm{m} / \mathrm{z} 46$ signal just before the peak) in gray. The background values show a rapid increase with decreasing temperature below $-140^{\circ} \mathrm{C}$. We found that the air $\left(\mathrm{N}_{2}\right.$ and $\left.\mathrm{O}_{2}\right)$ peak that appears before the $\mathrm{CH}_{4}$ peak (see Fig. 2) increases with decreasing $\mathrm{T} 2$ temperature, especially temperatures below $-140^{\circ} \mathrm{C}$, and its tailing interferes with the $\mathrm{CH}_{4}$ peak.

\subsection{GC separations and combustion}

As reported by Tokida et al. (2014), we confirmed that GS-CarbonPLOT achieves better separation of $\mathrm{CH}_{4}$ from air $\left(\mathrm{N}_{2}\right.$ and $\left.\mathrm{O}_{2}\right)$ than a PoraPLOT Q column $(0.32 \mathrm{~mm}$ ID, $25 \mathrm{~m}, 10 \mu \mathrm{m}$ thickness, Agilent Technologies, USA), which was widely used by previous studies (e.g., Rice et al. 2001; Umezawa et al. 2009; Brass and Röckmann 2010).

Figure 7 shows the relationship of $\delta^{13} \mathrm{C}_{-} \mathrm{CH}_{4}$ and peak area with the temperature of the combustion furnace. It is clearly shown in the figure that $\mathrm{CH}_{4}$ com-

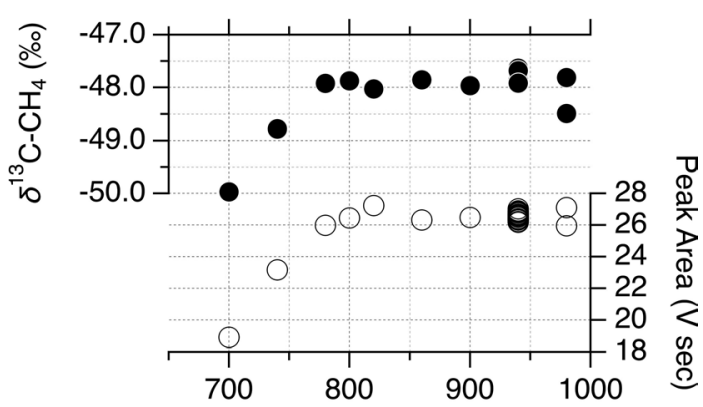

Combustion furnace temperature $\left({ }^{\circ} \mathrm{C}\right)$

Fig. 7. $\quad \delta^{13} \mathrm{C}-\mathrm{CH}_{4}$ (closed circles, left axis) and peak area (open circles, right axis) relationships as a function of combustion furnace temperature.

bustion is incomplete at furnace temperatures below $800^{\circ} \mathrm{C}$. Such incomplete combustion yields lower $\delta^{13} \mathrm{C}_{-} \mathrm{CH}_{4}$ values, indicative of isotope fractionation where lighter isotopologue ${ }^{12} \mathrm{CH}_{4}$ is preferentially combusted.

Re-oxidation of the furnace is carried out when a frequent $\delta^{13} \mathrm{C}_{-} \mathrm{CH}_{4}$ deviation of the measured value of the standard gas (typically $>\sim 0.2 \%$ off from the nominal value) was observed and their standard deviation becomes larger $(>\sim 0.2 \%)$. This happens typically at 3 weeks or longer, and we do not observe rapid daily shifts in $\delta^{13} \mathrm{C}_{-} \mathrm{CH}_{4}$ through repetitive measurements as seen by Tokida et al. (2014). The re-oxidation interval depends on how frequently the system is used for sample measurement. It was found that the system tends to provide a stable measurement during periods when daily operation is continued. We empirically surmise that regular eluting of small amounts of $\mathrm{O}_{2}$ contained in sample air helps in conditioning the furnace (Miller et al. 2002). In this respect, automation of CPR is advantageous for conditioning the system constantly, since the system can be operated even during periods not used for sample analysis (e.g., nighttime).

Schmitt et al. (2013) showed that atmospheric $\mathrm{Kr}$ can interfere with $\delta^{13} \mathrm{C}_{-} \mathrm{CH}_{4}$ measurement on IRMS. $\mathrm{Kr}$ is present in ambient air at $\sim 1 \mathrm{ppm}$, and physicochemical separation of $\mathrm{Kr}$ from $\mathrm{CH}_{4}$ is difficult (Schmitt et al. 2013). To eliminate the $\mathrm{Kr}$ interference, some laboratories have used a PCS column (Umezawa et al. 2018) because GC separation of $\mathrm{Kr}$ from $\mathrm{CO}_{2}$ (derived from $\mathrm{CH}_{4}$ ) is easier. Brand et al. (2016) pointed out that a portion of $\mathrm{CH}_{4}$ that was not combusted in the furnace could also interfere with $\delta^{13} \mathrm{C}$ measurement on IRMS, since $\mathrm{CH}_{4}^{+}$molecular ions formed in 
the ion source help the $\mathrm{CO}_{2}$ gas become protonated to $\mathrm{CO}_{2} \mathrm{H}^{+}$(i.e., isobaric with ${ }^{13} \mathrm{CO}_{2}^{+}$). They described that un-combusted $\mathrm{CH}_{4}$ should be separated from $\mathrm{CO}_{2}$ by using a PCS column. It is noted that our PCS column $(50 \mathrm{~m})$ could be shorter. We achieved the necessary precision with this column along with examinations of other various component settings, but our tests indicated that columns PoraPLOT Q (0.32 mm ID, 25 $\mathrm{m}$ length, $5 \mu \mathrm{m}$ thickness, Agilent Technologies) and GS-Carbon PLOT $(0.32 \mathrm{~mm}$ ID, $30 \mathrm{~m}$ length, $3 \mu \mathrm{m}$ thickness, Agilent Technologies) are also capable of separating $\mathrm{Kr}$ from $\mathrm{CH}_{4}$-derived $\mathrm{CO}_{2}$. The former was used by Brand et al. (2016), and the latter was used by Tokida et al. (2014), although the lengths of the PCS columns are different in these studies because of different settings of column temperature.

\subsection{Chromatogram}

A typical chromatogram shows a significant intensity of the air peak (Fig. 2). We confirmed the appearance of the air peak even with the combustion furnace kept at room temperature as reported by previous studies, and it has been suggested that this peak is due to $\mathrm{NO}, \mathrm{N}_{2} \mathrm{O}$, and $\mathrm{NO}_{2}$ produced in the ion source (Umezawa et al. 2009; Tokida et al. 2014). It is also noted that measurement of $\sim 2 \mathrm{ppm} \mathrm{CH}_{4}$ in $\mathrm{N}_{2}$ showed a slightly reduced intensity of the air peak, which indicates that the presence of $\mathrm{O}_{2}$ in sample air also plays a role. We note that the air peak intensity is reduced (but not completely removed) by disconnecting the sample open split until $950 \mathrm{~s}$. The $\mathrm{Kr}$ peak was identified by analyzing $\sim 10 \mathrm{ppm} \mathrm{Kr}$ in $\mathrm{N}_{2}$ (10 times ambient). It is also noted that, as reported by Sperlich et al. (2013) and Brand et al. (2016), multiple injections of $\mathrm{CO}_{2}$ reference gas are needed to condition the ion source and attain a more stable measurement. In our system, the first $\mathrm{CO}_{2}$ peak deviates by up to $\sim 0.5 \%$ in comparison to the last few peaks of the 10 injections.

\subsection{Calibration}

As described earlier, our current operation determines a sample $\delta^{13} \mathrm{C}-\mathrm{CH}_{4}$ value against a $\delta^{13} \mathrm{C}-\mathrm{CO}_{2}$ value assigned for the $\mathrm{CO}_{2}$ reference gas $(-32.460$ $\pm 0.007 \%$ o) injected in each measurement run. It is important that the reference $\mathrm{CO}_{2}$ gas has a $\delta^{13} \mathrm{C}$ value close to the sample's (about $-47 \%$ ); otherwise, measurement uncertainty could be increased because of the disparity of $\delta^{13} \mathrm{C}$ between the sample and reference. The $\mathrm{CO}_{2}$-based calibration strategy, like our current attempt, has been used by previous measurement systems (e.g., Rice et al. 2001; Morimoto et al. 2006; Umezawa et al. 2009), but we are aware that this does

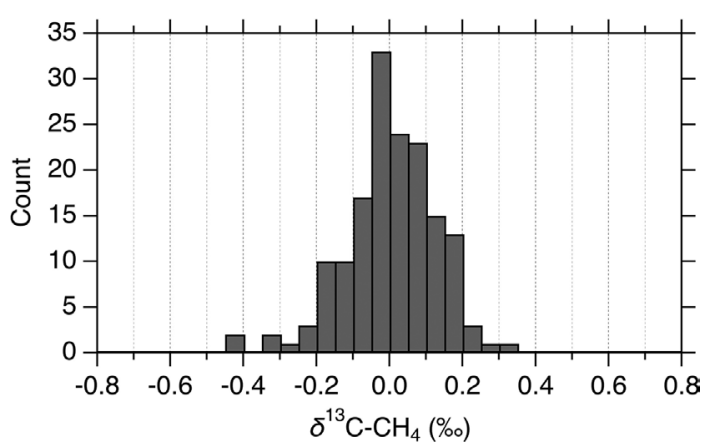

Fig. 8. A histogram of $\delta^{13} \mathrm{C}-\mathrm{CH}_{4}$ deviations from the average for a standard air measured from November 9, 2018, to January 21, $2019(N=158)$.

not follow the identical treatment principle between the sample and standard (Werner and Brand 2001). Thus, it cannot be free from fractionations that could occur during the entire processes in sample and reference lines and their day-to-day or longer-term variability (e.g., Miller et al. 2002). In the future, we are planning to assign a $\delta^{13} \mathrm{C}_{-} \mathrm{CH}_{4}$ value to the working standard air so that the measured value for a sample can be determined against the measurement of a standard that is treated in an identical manner to the sample. For this purpose, the apparatus for the precise calibration of $\delta^{13} \mathrm{C}_{-} \mathrm{CH}_{4}$ in the working standard, as was examined by Sperlich et al. $(2012,2016)$, is in preparation.

\subsection{Reproducibility}

As an indicator of reproducibility of our measurement system, Fig. 8 shows a histogram of $\delta^{13} \mathrm{C}_{-} \mathrm{CH}_{4}$ deviations from the average measured value for the working standard air. The measurements of the standard air were made between November 9, 2018, and January $21,2019(N=158)$. The standard deviation of all measurements is calculated to be $0.12 \%$. We also note that the standard deviation from repeated working standard air measurements within one day or a couple of days is better than $0.1 \%$.

\subsection{Automated outside air measurements}

Upstream of V3, CPR has a line that draws outside air via a metal bellows pump (MB-21, Senior Metal Bellows Corp., USA) (Fig. 1). The outside air inlet is located on the roof of a one-story building at NIES. By opening V3 and continuously introducing outside air, we made automated measurements for outside air in Tsukuba for the period November 9, 2018, to 

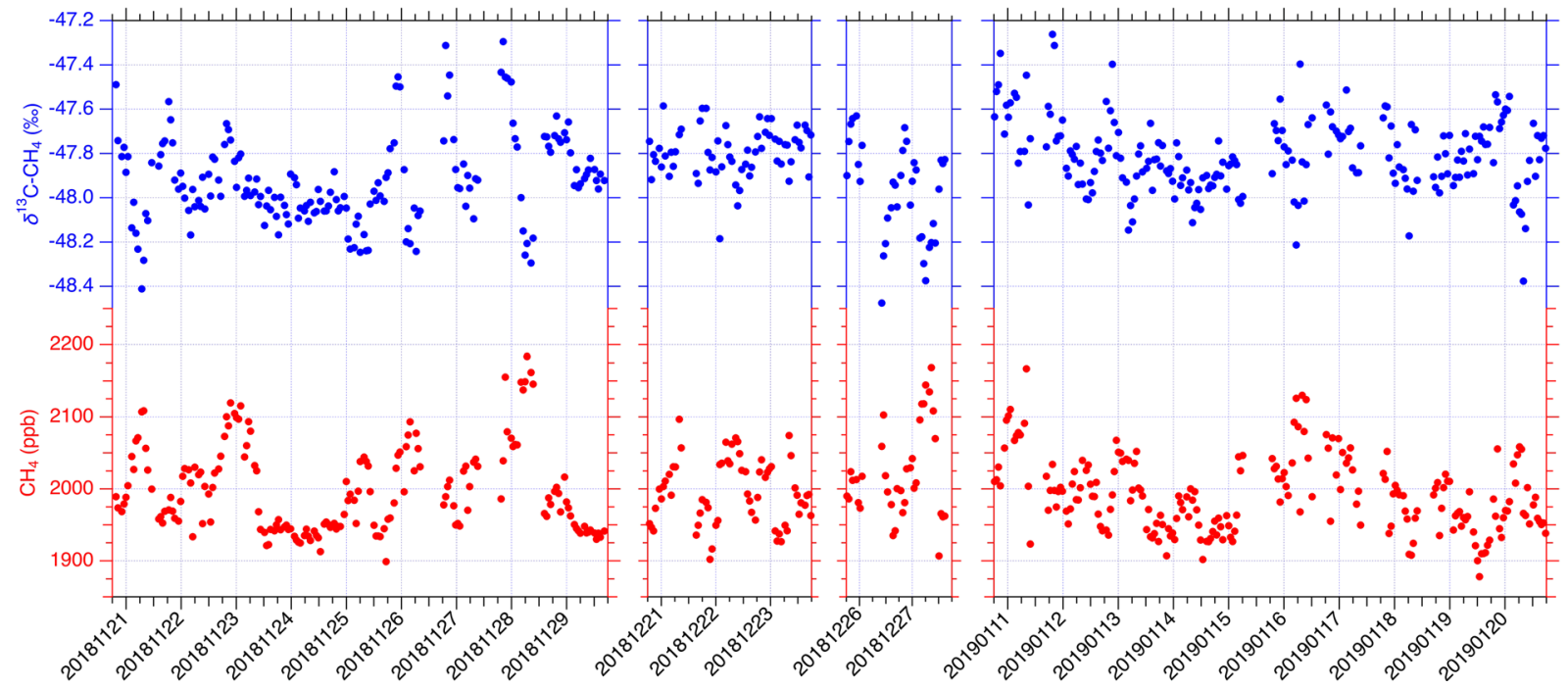

Fig. 9. Time series of $\delta^{13} \mathrm{C}_{-} \mathrm{CH}_{4}$ measurements (blue, upper left axis) for air outside the NIES building, Tsukuba. For reference, $\mathrm{CH}_{4}$ mole fractions determined by peak area are also shown (red, lower left axis).

January 19, 2019. The measurements were run mainly during the time when the system was not used for flask samples or test measurements. The measurement cycle (i.e., data interval) was $\sim 1 \mathrm{~h}$, and the standard air was analyzed at every 5 or 10 cycles. Figure 9 presents examples of measurement time-series. The $\mathrm{CH}_{4}$ mole fraction for outside air samples (red) was determined by peak area in comparison to those from the standard air measurements made before and after the sample. The measurement uncertainty of $\mathrm{CH}_{4}$ mole fraction by our system is estimated to be $1.2 \%$ ( $\sim 25 \mathrm{ppb})$. The $\mathrm{CH}_{4}$ mole fraction of the standard air was calibrated against laboratory $\mathrm{CH}_{4}$-in-air gases whose $\mathrm{CH}_{4}$ mole fraction was determined on the NIES-94 $\mathrm{CH}_{4}$ scale (Machida et al. 2008). We note that the results presented here are preliminary, but that they show an example of how our system can provide useful on-line $\delta^{13} \mathrm{C}_{-}-\mathrm{CH}_{4}$ data.

In the course of the two-month measurements, we observed diurnal and day-to-day variations in both $\mathrm{CH}_{4}$ mole fraction and $\delta^{13} \mathrm{C}_{-}-\mathrm{CH}_{4}$. The observed $\mathrm{CH}_{4}$ mole fraction and $\delta^{13} \mathrm{C}_{-} \mathrm{CH}_{4}$ ranged from 1850 to $2180 \mathrm{ppb}$ and -48.48 to $-47.26 \%$, respectively. To depict diurnal variations, Fig. 10 shows $\delta^{13} \mathrm{C}^{-\mathrm{CH}_{4}}$ and $\mathrm{CH}_{4}$ mole fraction as a function of time of day. It is obvious that the minimum $\mathrm{CH}_{4}$ mole fraction (maximum $\delta^{13} \mathrm{C}_{-}-\mathrm{CH}_{4}$ ) was nearly constant throughout the day (approximately $1900 \mathrm{ppb}$ or $-47.6 \%$ ), and the high $\mathrm{CH}_{4}$ mole fraction (low $\delta^{13} \mathrm{C}-\mathrm{CH}_{4}$ ) was observed almost exclusively during nighttime to morning. In

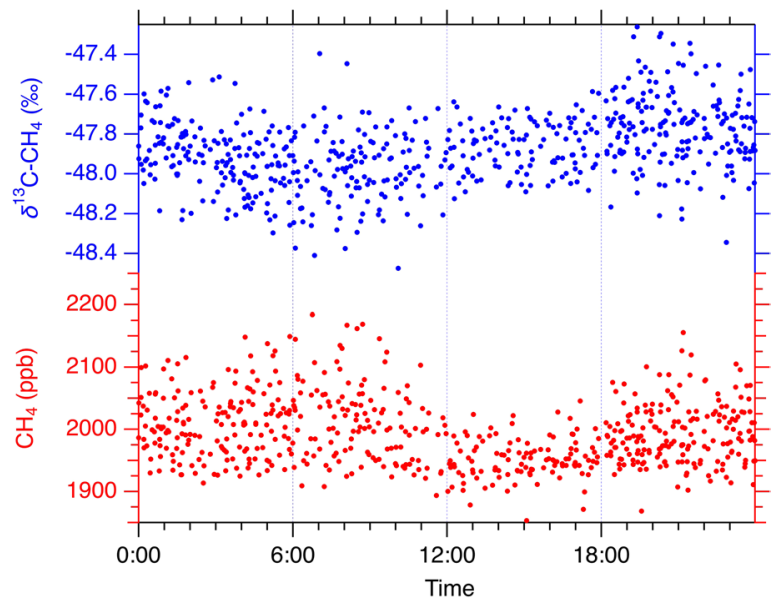

Fig. 10. Diurnal variations of $\delta^{13} \mathrm{C}-\mathrm{CH}_{4}$ (blue, upper left axis) and $\mathrm{CH}_{4}$ mole fraction (red, lower left axis) for air outside the NIES building, Tsukuba.

particular, we frequently observed an increase of the $\mathrm{CH}_{4}$ mole fraction overnight until around $10 \mathrm{am}$, accompanied by a decrease of $\delta^{13} \mathrm{C}_{-}-\mathrm{CH}_{4}$. The nighttime $\mathrm{CH}_{4}$ accumulation would be explained by build-up of the nocturnal boundary layer, and the $\mathrm{CH}_{4}$ decrease afterward would be due to the formation of the daytime convective mixed layer.

To infer $\mathrm{CH}_{4}$ sources contributing to the observed variations, some of the high $\mathrm{CH}_{4}$ events are plotted for 


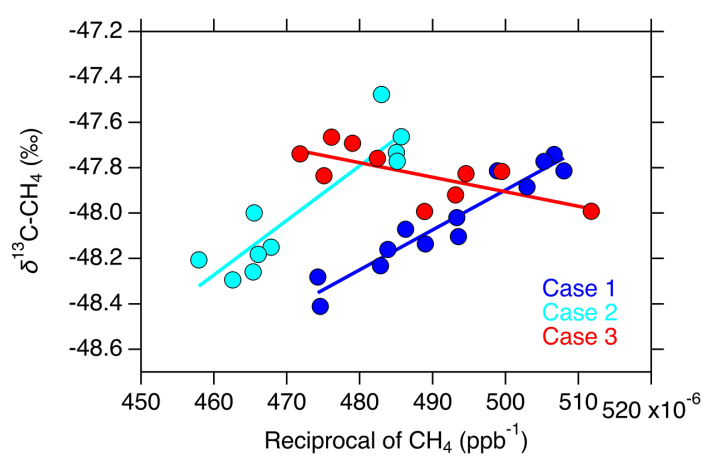

Fig. 11. A scatterplot of $\delta^{13} \mathrm{C}-\mathrm{CH}_{4}$ as a function of the reciprocal of the $\mathrm{CH}_{4}$ mole fraction for three cases during the observation period (Case 1 in blue, Case 2 in light blue, and Case 3 in red). The solid line is the least-square linear regression applied for each case.

$\delta^{13} \mathrm{C}_{-} \mathrm{CH}_{4}$ as a function of the reciprocal of the $\mathrm{CH}_{4}$ mole fraction (Fig. 11, often referred to as a Keeling plot). The isotope signature of the source has often been estimated by regression analysis of the Keeling plot according to the following equation (e.g., Pataki et al. 2003):

$$
\delta^{13} \mathrm{C}_{\text {obs }}=\delta^{13} \mathrm{C}_{\text {Source }}+\left(\delta^{13} \mathrm{C}_{B G D}-\delta^{13} \mathrm{C}_{\text {Source }}\right) \frac{\mathrm{C}_{B G D}}{\mathrm{C}_{o b s}},
$$

where the respective subscripts obs, Source, and $B G D$ denote the observed, source, and background $\mathrm{CH}_{4}$ mole fraction $\mathrm{C}$ or $\delta^{13} \mathrm{C}_{-} \mathrm{CH}_{4}$ values. This equation tells us that the intercept value of the regression line, obtained by plotting the observed $\delta^{13} \mathrm{C}_{-} \mathrm{CH}_{4}$ values against the reciprocal of the observed $\mathrm{CH}_{4}$ mole fraction, is the $\delta^{13} \mathrm{C}_{-} \mathrm{CH}_{4}$ signature of the source that exchanges $\mathrm{CH}_{4}$ with the overlying atmosphere. We selected two cases where a clear persistent $\mathrm{CH}_{4}$ increase with $\delta^{13} \mathrm{C}_{-} \mathrm{CH}_{4}$ decrease was observed from evening to the following morning: November 20-21 (Case 1) and 27-28 (Case 2). The Keeling plot analysis inferred source $\delta^{13} \mathrm{C}_{-} \mathrm{CH}_{4}$ signatures of $-56.7 \pm 0.8 \%$ (Case 1 , $R=0.96)$ and $-59.3 \pm 1.9 \%$ (Case $2, R=0.91$ ), and these two values correspond to microbial $\mathrm{CH}_{4}$ sources (Sherwood et al. 2017). There was another event when $\mathrm{CH}_{4}$ increased during the evening with $\delta^{13} \mathrm{C}_{-}-\mathrm{CH}_{4}$ (Case 3 , November 22); the source $\delta^{13}{\mathrm{C}-\mathrm{CH}_{4}}_{4}$ signature was estimated to be $-44.7 \pm 1.1 \%$ o $(R=-0.70)$, which is higher than those of microbial sources and rather fall within the range of fossil fuel sources (Sherwood et al. 2017). We also found four cases in November-
December when overnight $\mathrm{CH}_{4}$ increases were obvious but observed changes in $\delta^{13} \mathrm{C}_{-} \mathrm{CH}_{4}$ were smaller. These events showed relatively scattered Keeling plots (not shown) and inferred source $\delta^{13} \mathrm{C}^{-} \mathrm{CH}_{4}$ signatures ranging from $-46.6 \pm 1.4 \%$ to $-50.1 \pm 3.6 \%$. Possible nearby $\mathrm{CH}_{4}$ sources are a pond in the institute garden, natural gas use in nearby residential areas, exhaust gas from automobiles, and mixtures of these sources.

\subsection{Flask measurements}

As described earlier, when either pumped outside air or pressurized sample air stored in a flask is analyzed, the sample air comes into the system by opening V3, and it flows through MFC1, Nafion and Ascarite traps, and T1, with the four-port valve kept at the ON position (solid line), in reference to Fig. 1. This means that it is the pressure of the sample air itself (V3 upstream) that allows flow through T1 and preconcentration of $\mathrm{CH}_{4}$ in the sample air (air-flow mode). Our system has an additional measurement mode. By opening V2 and switching the four-port valve to the OFF position (dashed line), carrier $\mathrm{He}$ gas pushes sample air in the flask and allows it to flow through $\mathrm{T} 1$ for preconcentration of $\mathrm{CH}_{4}$ (He-flow mode). This measurement mode is used when the internal pressure of an air sample flask is close to the ambient pressure or below. For instance, we sometimes split aliquots of air samples (originally collected at $\sim 0.15 \mathrm{MPa}$ ) into $100-\mathrm{mL}$ sample flasks at around ambient pressure for archive because the original sample flasks used for our air sampling networks should be routinely circulated for sample collection and measurement of various species. Such tentative archive of an air sample allows more flexibility in $\delta^{13} \mathrm{C}_{-} \mathrm{CH}_{4}$ measurements. It is noted that both air-flow (Eyer et al. 2016; Brand et al. 2016) and He-flow (Rice et al. 2001; Miller et al. 2002; Brass and Röckmann 2010; Morimoto et al. 2006; Umezawa et al. 2009) modes have been used previously in continuous-flow $\delta{ }^{13} \mathrm{C}-\mathrm{CH}_{4}$ measurements.

To confirm the consistency of measurement results between both modes, the working standard air was filled into $100-\mathrm{mL}$ flasks, and those flask samples were analyzed in He-flow mode to compare with measurements in air-flow mode. In our standard method, the standard air flows through $\mathrm{T} 1$ for $10 \mathrm{~min}$, with MFC1 set to $10 \mathrm{~mL} \mathrm{~min}{ }^{-1}$, which preconcentrates $\mathrm{CH}_{4}$ in a gas volume of $100 \mathrm{~mL}$ on T1. Although this volume is equivalent to the standard air filled in a $100 \mathrm{~mL}$ flask at ambient pressure, our tests indicated that a 10-min He flow is not sufficient to completely flush the 
$100-\mathrm{mL}$ flask. It was found that 20-min He flushing of a sample flask is appropriate, and the measurement results are in agreement with those at air-flow mode. For two successive days, we found the differences in the measurements between both modes to be $0.05 \pm$ $0.10 \%$ and $0.01 \pm 0.08 \%$.

\section{Conclusion}

We set up a new measurement system for $\delta^{13} \mathrm{C}-\mathrm{CH}_{4}$ based on continuous-flow isotope ratio mass spectrometry. By using a custom-made preconcentration and refocusing trap system with Stirling coolers, our system requires no cryogen, which is highly advantageous in automated and unattended operation. Repetitive measurements indicated that the reproducibility of the system is $0.12 \%$. We performed automated continuous measurements of ambient air outside our laboratory building for 2 months. The results showed clear diurnal variations of $\mathrm{CH}_{4}$ mole fractions and $\delta^{13} \mathrm{C}^{-\mathrm{CH}_{4}}$ with amplitudes of $>200 \mathrm{ppb}$ and $>0.6 \%$, respectively, which demonstrates that the variability of such amplitudes can be well characterized by our measurement. Since our system is capable of measuring air samples stored at both above and below ambient pressure, it is well optimized for monitoring operation using various flask air samples collected by existing air sampling networks. Future measurement operation will provide a number of atmospheric $\delta^{13} \mathrm{C}_{-}-\mathrm{CH}_{4}$ data to the atmospheric science community. Accurate calibration of the standard air is our future task.

\section{Acknowledgments}

We are grateful to Yasunori Tohjima, Akihiko Ito and Yukio Terao for discussion during the set-up of the measurement system. We thank Hitoshi Mukai for $\delta^{13} \mathrm{C}$ measurements of $\mathrm{CO}_{2}$ and Keiichi Katsumata for help in preparing the working standard air and the CPR-FID set-up. This work has been supported by the Environmental Research and Technology Development Fund (2-1710) of the Ministry of the Environment, Japan and Environmental Restoration and Conservation Agency.

\section{References}

Bousquet, P., P. Ciais, J. B. Miller, E. J. Dlugokencky, D. A. Hauglustaine, C. Prigent, G. R. Van der Werf, P. Peylin, E.-G. Brunke, C. Carouge, R. L. Langenfelds, J. Lathiére, F. Papa, M. Ramonet, M. Schimidt, L. P. Steele, S. C. Tyler, and J. White, 2006: Contribution of anthropogenic and natural sources to atmospheric methane variability. Nature, 443, 439-443.

Brand, W. A., M. Rothe, P. Sperlich, M. Strube, and M.
Wendeberg, 2016: Automated simultaneous measurement of the $\delta^{13} \mathrm{C}$ and $\delta^{2} \mathrm{C}$ values of methane and the $\delta^{13} \mathrm{C}$ and $\delta^{18} \mathrm{O}$ values of carbon dioxide in flask samples using a new multi cryo-trap/gas chromatography/ isotope ratio mass spectrometry system. Rapid Commun. Mass Spectrom., 30, 1523-1539.

Brass, M., and T. Röckmann, 2010: Continuous-flow isotope ratio mass spectrometry method for carbon and hydrogen isotope measurements on atmospheric methane. Atmos. Meas. Tech., 3, 1707-1721.

Cunnold, D. M., L. P. Steele, P. J. Fraser, P. G. Simmonds, R. G. Prinn, R. F. Weiss, L. W. Porter, S. O'Doherty, R. L. Langenfelds, P. B. Krummel, H. J. Wang, L. Emmons, X. X. Tie, and E. J. Dlugokencky, 2002, In situ measurements of atmospheric methane at GAGE/ AGAGE sites during 1985-2000 and resulting source inferences. J. Geophys. Res., 107, 4225, doi:10.1029/ 2001JD001226.

Dlugokencky, E. J., E. G. Nisbet, R. Fisher, and D. Lowry, 2011: Global atmospheric methane: Budget, changes and dangers. Philos. Trans. R. Soc. A, 369, 2058-2072.

Eyer, S., N. P. Stadie, A. Borgschulte, L. Emmenegger, and J. Mohn, 2014: Methane preconcentration by adsorption: A methodology for materials and conditions selection. Adsorption, 20, 657-666.

Eyer, S., B. Tuzson, M. E. Popa, C. van der Veen, T. Röckmann, M. Rothe, W. A. Brand, R. Fisher, D. Lowry, E. G. Nisbet, M. S. Brennwald, E. Harris, C. Zellweger, L. Emmenegger, H. Fischer, and J. Mohn, 2016: Real-time analysis of $\delta^{13} \mathrm{C}$ - and $\delta \mathrm{D}-\mathrm{CH}_{4}$ in ambient air with laser spectroscopy: Method development and first intercomparison results. Atmos. Meas. Tech., 9, 263-280.

Fujita, R., S. Morimoto, T. Umezawa, K. Ishijima, P. K. Patra, D. E. J. Worthy, D. Goto, S. Aoki, and T. Nakazawa, 2018: Temporal variations of the mole fraction, carbon and hydrogen isotope ratios of atmospheric methane in the Hudson Bay Lowlands, Canada. $J$. Geophys. Res., 123, 4695-4711.

Ito, A., Y. Tohjima, T. Saito, T. Umezawa, T. Hajima, R. Hirata, M. Saito, and Y. Terao, 2019: Methane budget of East Asia, 1990-2015: A bottom-up evaluation. Sci. Total Environ., 676, 40-52.

Levin, I., H. Glatzel-Mattheier, T. Marik, M. Cuntz, and M. Schmidt, 1999: Verification of German methane emission inventories and their recent changes based on atmospheric observations. J. Geophys. Res., 104, 3447-3456.

Lowe, D. C., C. A. M. Brenninkmeijer, S. C. Tyler, and E. J. Dlugokencky, 1991: Determination of the isotopic composition of atmospheric methane and its application in the Antarctic. J. Geophys. Res., 96, 1545515467.

Lowry, D., C. W. Holmes, N. D. Rata, P. O'Brien, and E. G. Nisbet, 2001: London methane emissions: Use of diurnal changes in concentration and $\delta^{13} \mathrm{C}$ to identify 
urban sources and verify inventories. J. Geophys. Res., 106, 7427-7448.

Machida, T., H. Matsueda, Y. Sawa, Y. Nakagawa, K. Hirotani, N. Kondo, K. Goto, T. Nakazawa, K. Ishikawa, and T. Ogawa, 2008: Worldwide measurements of atmospheric $\mathrm{CO}_{2}$ and other trace gas species using commercial airlines. J. Atmos. Oceanic Technol., 25, 1744-1754.

Merritt, D. A., J. M. Hayes, and D. J. Des Marais, 1995: Carbon isotopic analysis of atmospheric methane by isotope-ratio-monitoring gas chromatography-mass spectrometry. J. Geophys. Res., 100, 1317-1326.

Mikaloff Fletcher, S. E., P. P. Tans, L. M. Bruhwiler, J. B. Miller, and M. Heimann, 2004: $\mathrm{CH}_{4}$ sources estimated from atmospheric observations of $\mathrm{CH}_{4}$ and its ${ }^{13} \mathrm{C} /{ }^{12} \mathrm{C}$ isotopic ratios: 1. Inverse modeling of source processes. Global Biogeochem. Cycles, 18, GB4004, doi: 10.1029/2004GB002223.

Miller, J. B., K. A. Mack, R. Dissly, J. W. C. White, E. J. Dlugokencky, and P. P. Tans, 2002: Development of analytical methods and measurements of ${ }^{13} \mathrm{C} /{ }^{12} \mathrm{C}$ in atmospheric $\mathrm{CH}_{4}$ from the NOAA Climate Monitoring and Diagnostics Laboratory Global Air Sampling Network. J. Geophys. Res., 107, 4178, doi:10.1029/ 2001JD000630.

Morimoto, S., S. Aoki, T. Nakazawa, and T. Yamanouchi, 2006: Temporal variations of the carbon isotopic ratio of atmospheric methane observed at Ny Ålesund, Svalbard from 1996 to 2004. Geophys. Res. Lett., 33, L01807, doi:10.1029/2005GL024648.

Mukai, H., 2005: Inter-comparison of isotope ratios for $\mathrm{CO}_{2}$ using several reference materials. World Meteorological Organization Global Atmosphere Watch. No. 161, 12th WMO/IAEA Meeting of Experts on Carbon Dioxide Concentration and Related Tracers Measurement Techniques, 58-63. [Available at https://ibrary. wmo.int/doc_num.php?explnum_id=9298.]

Nisbet, E. G., E. J. Dlugokencky, M. R. Manning, D. Lowry, R. E. Fisher, J. L. France, S. E. Michel, J. B. Miller, J. W. C. White, B. Vaughn, P. Bousquet, J. A. Pyle, N. J. Warwick, M. Cain, R. Brownlow, G. Zazzeri, M. Lanoisellé, A. C. Manning, E. Gloor, D. E. J. Worthy, E.-G. Brunke, C. Labuschagne, E. W. Wolff, and A. L. Ganesan, 2016: Rising atmospheric methane: 20072014 growth and isotopic shift. Global Biogeochem. Cycles, 30, 1356-1370.

Nisbet, E. G., M. R. Manning, E. J. Dlugokencky, R. E. Fisher, D. Lowry, S. E. Michel, C. Lund Myhre, S. M. Platt, G. Allen, P. Bousquet, R. Brownlow, M. Cain, J. L. France, O. Hermansen, R. Hossaini, A. E. Jones, I. Levin, A. C. Manning, G. Myhre, J. A. Pyle, B. H. Vaughn, N. J. Warwick, and J. W. C. White, 2019: Very Strong Atmospheric Methane Growth in the 4 Years 2014-2017: Implications for the Paris Agreement. Global Biogeochem. Cycles, 33, 318-342.

Pataki, D. E., J. R. Ehleringer, L. B. Flanagan, D. Yakir, D. R.
Bowling, C. J. Still, N. Buchmann, J. O. Kaplan, and J. A. Berry, 2003: The application and interpretation of Keeling plots in terrestrial carbon cycle research. Global Biogeochem. Cycles, 17, 1022.

Quay, P., J. Stutsman, D. Wilbur, A. Snover, E. Dlugokencky, and T. Brown, 1999: The isotopic composition of atmospheric methane. Global Biogeochem. Cycles, 13, 445-461.

Rice, A. L., A. A. Gotoh, H. O. Ajie, and S. C. Tyler, 2001: High-precision continuous-flow measurement of $\delta^{13} \mathrm{C}$ and $\delta \mathrm{D}$ of atmospheric $\mathrm{CH}_{4}$. Anal. Chem., 73, 41044110 .

Rice, A. L., C. L. Butenhoff, D. G. Teama, F. H. Röger, M. A. K. Khalil, and R. A. Rasmussen, 2016: Atmospheric methane isotopic record favors fossil sources flat in 1980 s and 1990s with recent increase. Proc. Natl. Acad. Sci. U.S.A., 113, 10791-10796.

Rigby, M., R. G. Prinn, P. J. Fraser, P. G. Simmonds, R. L. Langenfelds, J. Huang, D. M. Cunnold, L. P. Steele, P. B. Krummel, R. F. Weiss, S. O'Doherty, P. K. Salameh, H. J. Wang, C. M. Harth, J. Mühle, and L. W. Porter, 2008: Renewed growth of atmospheric methane. Geophys. Res. Lett., 35, L22805, doi:10.1029/ 2008 GL036037.

Rigby, M., S. A. Montzka, R. G. Prinn, J. W. C. White, D. Young, S. O’Doherty, M. F. Lunta, A. L. Ganesan, A. J. Manning, P. G. Simmonds, P. K. Salameh, C. M. Harth, J. Mühle, R. F. Weiss, P. J. Fraser, L. P. Steele, P. B. Krummel, A. McCulloch, and S. Park, 2017: Role of atmospheric oxidation in recent methane growth. Proc. Natl. Acad. Sci. U.S.A., 114, 5373-5377.

Röckmann, T., S. Eyer, C. van der Veen, M. E. Popa, B. Tuzson, G. Monteil, S. Houweling, E. Harris, D. Brunner, H. Fischer, G. Zazzeri, D. Lowry, E. G. Nisbet, W. A. Brand, J. M. Necki, L. Emmenegger, and J. Mohn, 2016: In situ observations of the isotopic composition of methane at the Cabauw tall tower site. Atmos. Chem. Phys., 16, 10469-10487.

Saito, T., and Y. Yokouchi, 2008: Stable carbon isotope ratio of methyl chloride emitted from glasshouse-grown tropical plants and its implication for the global methyl chloride budget. Geophys. Res. Lett., 35, L08807, doi:10.1029/2007GL032736.

Saunois, M., P. Bousquet, B. Poulter, A. Peregon, P. Ciais, J. G. Canadell, E. J. Dlugokencky, G. Etiope, D. Bastviken, S. Houweling, G. Janssens-Maenhout, F. N. Tubiello, S. Castaldi, R. B. Jackson, M. Alexe, V. K. Arora, D. J. Beerling, P. Bergamaschi, D. R. Blake, G. Brailsford, V. Brovkin, L. Bruhwiler, C. Crevoisier, P. Crill, K. Covey, C. Curry, C. Frankenberg, N. Gedney, L. Höglund-Isaksson, M. Ishizawa, A. Ito, F. Joos, H.-S. Kim, T. Kleinen, P. Krummel, J.-F. Lamarque, R. Langenfelds, R. Locatelli, T. Machida, S. Maksyutov, K. C. McDonald, J. Marshall, J. R. Melton, I. Morino, V. Naik, S. O'Doherty, F.-J. W. Parmentier, P. K. Patra, C. Peng, S. Peng, G. P. Peters, I. Pison, C. Prigent, R. 
Prinn, M. Ramonet, W. J. Riley, M. Saito, M. Santini, R. Schroeder, I. J. Simpson, R. Spahni, P. Steele, A. Takizawa, B. F. Thornton, H. Tian, Y. Tohjima, N. Viovy, A. Voulgarakis, M. van Weele, G. R. van der Werf, R. Weiss, C. Wiedinmyer, D. J. Wilton, A. Wiltshire, D. Worthy, D. Wunch, X. Xu, Y. Yoshida, B. Zhang, Z. Zhang, and Q. Zhu, 2016: The global methane budget 2000-2012. Earth Syst. Sci. Data, 8, 697-751.

Schaefer, H., S. E. Mikaloff Fletcher, C. Veidt, C., K. R. Lassey, G. W. Brailsford, T. M. Bromley, E. J. Dlugokencky, S. E. Michel, J. B. Miller, I. Levin, D. C. Lowe, R. J. Martin, B. H. Vaughn, and J. W. C. White, 2016: A 21st-century shift from fossil-fuel to biogenic methane emissions indicated by ${ }^{13} \mathrm{CH}_{4}$. Science, 352, 80-84.

Schmitt, J., B. Seth, M. Bock, C. van der Veen, L. Möller, C. J. Sapart, M. Prokopiou, T. Sowers, T. Röckmann, and H. Fischer, 2013: On the interference of $\mathrm{Kr}$ during carbon isotope analysis of methane using continuousflow combustion-isotope ratio mass spectrometry. Atmos. Meas. Tech., 6, 1425-1445.

Schwietzke, S., O. A. Sherwood, L. M. P. Bruhwiler, J. B. Miller, G. Etiope, E. J. Dlugokencky, S. E. Michel, V. A. Arling, B. H. Vaughn, J. W. C. White, and P. P. Tans, 2016: Upward revision of global fossil fuel methane emissions based on isotope database. Nature, 538, 88-91.

Sherwood, O. A., C. Schwietzke, V. A. Arling, and G. Etiope, 2017: Global inventory of gas geochemistry data from fossil fuel, microbial and burning sources, version 2017. Earth Syst. Sci. Data, 9, 639-656.

Sperlich, P., M. Guillevic, C. Buizert, T. M. Jenk, C. J. Sapart, H. Schaefer, T. J. Popp, and T. Blunier, 2012: A combustion setup to precisely reference $\delta^{13} \mathrm{C}$ and $\delta^{2} \mathrm{C}$ isotope ratios of pure $\mathrm{CH}_{4}$ to produce isotope reference gases of $\delta^{13} \mathrm{C}-\mathrm{CH}_{4}$ in synthetic air. Atmos. Meas. Tech., 5, 2227-2236.

Sperlich, P., C. Buizert, T. M. Jenk, C. J. Sapart, M. Prokopiou, T. Röckmann, and T. Blunier, 2013: An automated GC-C-GC-IRMS setup to measure palaeoatmospheric $\delta^{13} \mathrm{C}-\mathrm{CH}_{4}, \delta^{15} \mathrm{~N}-\mathrm{N}_{2} \mathrm{O}$ and $\delta^{18} \mathrm{O}-\mathrm{N}_{2} \mathrm{O}$ in one ice core sample. Atmos. Meas. Tech., 6, 2027-2041.

Sperlich, P., N. A. M. Uitslag, J. M. Richter, M., Rothe, H. Geilmann, C. van der Veen, T. Röckmann, T. Blunier, and W. A. Brand, 2016: Development and evaluation of a suite of isotope reference gases for methane in air. Atmos. Meas. Tech., 9, 3717-3737.

Stevens, C. M., and F. E. Rust, 1982: The carbon isotopic composition of atmospheric methane. J. Geophys. Res., 87, 4879-4882.

Tokida, T., Y. Nakajima, K. Hayashi, Y. Usui, N. Katayanagi, M. Kajiura, H. Nakamura, and T. Hasegawa, 2014: Fully automated, high-throughput instrumentation for measuring the $\delta^{13} \mathrm{C}$ value of methane and application of the instrumentation to rice paddy samples. Rapid Commun. Mass Spectrom., 28, 2315-2324.

Turner, A. J., C. Frankenberg, P. O. Wennberg, and D. J. Jacob, 2017: Ambiguity in the causes for decadal trends in atmospheric methane and hydroxyl. Proc. Natl. Acad. Sci. U.S.A., 114, 5367-5372.

Umezawa, T., S. Aoki, T. Nakazawa, and S. Morimoto, 2009: A High-precision measurement system for carbon and hydrogen isotopic ratios of atmospheric methane and its application to air samples collected in the western Pacific region. J. Meteor. Soc. Japan, 87, 365-379.

Umezawa, T., T. Machida, S. Aoki, and T. Nakazawa, 2012: Contributions of natural and anthropogenic sources to atmospheric methane variations over western Siberia estimated from its carbon and hydrogen stable isotopes. Global Biogeochem. Cycles, 26, GB4009, doi: 10.1029/2011GB004232.

Umezawa, T., C. A. M. Brenninkmeijer, T. Röckmann, C. van der Veen, S. C. Tyler, R. Fujita, S. Morimoto, S. Aoki, T. Sowers, J. Schmitt, M. Bock, J. Beck, H. Fischer, S. E. Michel, B. H. Vaughn, J. B. Miller, J. W. C. White, G. Brailsford, H. Schaefer, P. Sperlich, W. A. Brand, M. Rothe, T. Blunier, D. Lowry, R. E. Fisher, E. G. Nisbet, A. L. Rice, P. Bergamaschi, C. Veidt, and I. Levin, 2018: Interlaboratory comparison of $\delta^{13} \mathrm{C}$ and $\delta \mathrm{D}$ measurements of atmospheric $\mathrm{CH}_{4}$ for combined use of data sets from different laboratories. Atmos. Meas. Tech., 11, 1207-1231.

Werner, R. A., and W. A. Brand, 2001: Referencing strategies and techniques in stable isotope ratio analysis. Rapid Commun. Mass Spectrom., 15, 501-519.

World Meteorological Organization, 2018: 19th WMO/IAEA Meeting on carbon dioxide, Other Greenhouse Gases and Related Measurement Techniques (GGMT-2017). GAW report No. 242, Crotwell, A., and M. Steinbacher (eds.), $134 \mathrm{pp}$.

Zazzeri, G., D. Lowry, R. E. Fisher, J. L. France, M. Lanoisellé, C. S. B. Grimmond, and E. G. Nisbet, 2017: Evaluating methane inventories by isotopic analysis in the London region. Sci. Rep., 7, 4854, doi:10.1038/ s41598-017-04802-6. 